\title{
Artistic Discourse and Rhetoric Means
}

\author{
Mammedli Aysel Ilqar ${ }^{1}$ \\ ${ }^{1}$ Department of English Stylistics, Azerbaijan University of Languages, Azerbaijan \\ Correspondence: Mammedli Aysel Ilgar, Department of English Stylistics, Azerbaijan University of Languages, \\ Azerbaijan. E-mail: ayselmammedli@box.az
}

Received: October 4, $2015 \quad$ Accepted: November 16, $2015 \quad$ Online Published: November 30, 2015
doi:10.5539/ijel.v5n6p164
URL: http://dx.doi.org/10.5539/ijel.v5n6p164

\begin{abstract}
The article investigates the rhetoric means that are used to adorn the artistic discourse. Adorning of the speech means to delever the artistic discourse to a reader by using various rhetoric means. This problem involved the attention of the rhetorics in ancient Greek, Rome etc., and they have interesting thoughts about adorning the speech by using rhetoric means. In those times the stated problem was introduced on political, law-court, and other speeches. In modern times this problem is also in the air. As the cognitive linguitics developes the problem that was proposed by the Roma rhetorics are investigated basing on conscious, mind frames. The article deals with the three main factors that can be introduced by a speaker. They are admonition, evocation and inspiration. These three factors have special importance in the artistic discourse. So, to adorn the speech is the main rhetoric means. The author states that the adorned speech gives the reader a special kind of inspiration and attracts the reader's attention more effectively. Different lexical and syntactical constructions (for example, word order, lexical repetitions, inversion, chiasm etc.) as well as colorful figurative can be used as rhetorical means. The author tries to explain the importance of rhetoric means in the artistic discourse using some of the rhetoric means in the article. Gesture, mimics and others can also help to increase the effectiveness of the speech.

Having investigated the problem the author comes to the conclusion using the figurative, rhetoric means the speaker tries to increase the effectiveness of the information. The author claims that if the artistic discourse is attractive, the listener listens to it attentively, believes in it and remembers it easily. To create the figurative speech means that not depending on the educational level everyone perceives the speech and enjoys listening to it.
\end{abstract}

Keywords: artistic, rhetoric means, discourse, text, meaning, figurative, information, effectiveness

\section{Introduction}

The terms of discourse and discourse analyses have been investigated by different linguistics for a long time, and it draws our attention. The cultural study, the literary theory, the history of an idea can be added to the source of investigation of the discourse. Actually, it should not be forgotten that discourse can also be studied by sociolinguistics, psychologists, and others. The investigated notion of the discourse appears as the object of the term. According to the investigations we can come to the conclusion that discourse can be observed in the multimodal and multimedia forms of the sign languages; it can also be seen both in the oral and written forms of the communication. R. Langaker wrote about the determination of the discourse: "Discourse is such an object of propaganda that it represents the world in itself which was created by the subject." He claims that the environment is not directly given to a man. The man himself creates it, and then comments about it. He states that we create the world in our minds ourselves (Mammadov \& Mammadov, 2010). A.Mammedov and M.Mammedov state both the importance of attention and mutual relations in auditorium while determining the discourse. It is undeniable that how to start a conversation and how to end is important in every discourse (Mammadov \& Mammadov, 2010).

\section{Scope of the Study}

Linguists study various aspects of the discourse, and try to explain it using different ways. For instance, sociolinguistics are interested in investigating the essence of social relations in discourse, psychologists are mostly eager how to master the language using the discourse, etc. They are interested in studying the tight methodology that is formed basing on experimental psychology. The aim of the methodology is to study the problems of sequence while studying them in mini texts, or in sentences. Generally, studying discourse means to 
clarify how human beings use the language for the purpose of communication, especially it clarifies the messages that the speakers, listeners etc. send to each other.

The functional-cognitive approach to the discourse that has been organized for some certain purposes is not only based on the langauge facts but also to the pragmatic purposes, to the cognitive ability of the receiver, to the practice of intercultural relations and background knowledges. The cognitive knowledge that organizes the formation of the discourse can be grouped as the followings:

1. the person who forms the discourse uses his cognitive knowledge for involving foreign culture;

2. the person uses his new knowledge about foreign culture in forming the discourse;

3. Undestanding the foreign culture he uses new knowledge about his culture in forming the discourse. The point that helps the meaning of the discourse be clear is not the decorded informaton, it is the social context that creates the situation of the communication (Mammadov \& Mammadov, 2010).

According to N. Enkvist we should like to state once more that discourse is considered to be the synthesis of a text together with the existing context in a social life. The text gets the meaning inside the context (Enkvist, 1989). Connected with this we remember the idea mentioned by L. Wittgenstein that meanings are formed namely in usage. So, the context is used for some special purposes by a sender, in certain conditions and with some certain meanings (Wittengstein, 1953). Dijk Teun A. van writes:

The context covers the participants that take part in the communication and it also consists of their roles, their purposes, their intentions and their common background knowledge (p. 23).

R.Wodak defines four levels of the context (Wodak, 1992)

1. The relations among sentences, texts, genres, and the relations between discourses;

2. Extra linguistic, social/sociological types;

3. The history of texts and organizations and their archeology;

4. The institutional frames of specific contexts related with the context.

According to the stated facts R.Wodak comes to the following conclusion:

With these we can investigate how the discourses, genres and texts change depending on the social-situational context (Wodak, 1992)

N. Zaychikova states three facts related with the discourse (Zaychikova, 2003)

1. Discourse is realized in the text.

2. Discourse has its cognitive base.

3. Discourse is characterized by ideology.

While investigating various types of the discourse such as artistic, media, law etc. we observe that each of them has its cognitive, pragmatic, ideological and cultural motivation. Some of these types exist in the real world, some do not. Some rely only on the writer's imagination, fantasy, etc. Artistic discourse is such a kind of discourse. All types of the discourse have their pragmatic meanings. But we can observe the differentness in their realization and tendency. The texts of the political and the law discourse seem more persuasive, more effective and even they have more tendencies to the manipulation than the texts of the artistic or scientific discourse. We should like to draw your attention to the artistic discourse. Here the main problem is the inside world of the sender of the artistic discourse (a writer or a poet), the psychological moment of his/her while wring the novel, his/her thinking style, his/her tendency to the literature etc. (For instance, in this moment we had better compare S. Maugham and E. Hemingway) The person's inner self plays a very important role in the meaning of the discourse. The true meaning of the discourse depends on the inside world of the person. The inside context is seen in mutual influence while communicating and depending on various corresponding cultural values. It is necessary to state the fact that the inside context of a person is the knowledge related with person's individual knowledge about the real world (Mammadov \& Mammadov, 2010).

I. Qalperin justly writes about the successful combination of functions of ethnic, cognitive and actual information in the artistic discourse (Halperin, 1981). It can also be concerned with other types of discourse such as political and law discourse. A. Mammedov and M. Mammedov write that using such kinds of discourses the sender of the texts try to persuade the receiver of the text to think a little more about the received information (Mammadov \& Mammadov, 2010). 
As we know the three kinds of the artistic discourse are distinguished. They are lyric, epic and dramatic. The modality is mostly observed in the lyric type of the artistic discourse. The combination of time and place is observed in this discourse. It means that the moment of narration is realized at the same time when the conversation is going on. It doesn't depend on the time when discourse began; the narration is realized at the time when it is perceived by the reader.

The author uses the metaphoric style in the lyric type of the discourse. In this type the author's "me" stands in the first place not depending on the organization of the text. There exist the tight relation between the speaker and a lyric hero. The attitude to the reality can be observed in the speaking process of the novel as well (Abdullayev, 2013)

The lingvocultural knowledge takes part in understanding any type of the discourse, and this lingvocultural knowledge which is reflected or is not reflected in any concrete text can help to understand the discourse. The art reality is identified and realized with real reality by the poetics of the novel, the literary organization of the novel, the systems of figurative and by the totality of them.

Each unit of the discourse is related with other one through its relation according to the completeness of the meaning. These relations are called rhetoric relations. Rhetoric relations are used by the sender of the text for to get some purposes while sending the information. The discourse unit can consist of maximal volume to the minimal volume. The sender of the text influences the receiver of the text using various rhetoric means. The rhetoric means directs the receiver to the poetic and literary activity. This process creates the conditions for fulfilling different communication functions. As we mentioned above it includes grammatical and lexical elements and events, as well as stylistic figures, personal names, the names of places, fiction and other names. These means create conditions for specific hidden meanings in the receivers of the text, and they also help to develop the receiver's cognitive knowledge.

F. Y. Veyselli states that the lexical, grammatical, phonetic means, as well as the intonation play a very important role in forming the inside relations of the discourse. Of course, in the oral form here belong paralinguistic manners (such as the movements of the body organs, the mimics etc.), in the written form here belong punctuation marks (such as full stop, comma, colons, exclamation marks, question mark etc.). Let us look such an example:

Tom went to report to Aunt Poly. She was sitting beside an open window. She was half asleep, and she was holding the sleeping cat. She was surprised to see Tom. She thought that he had run away from his work long ago.

In this small extract the personal pronoun /she/ connects separate parts that complete each other in the content. It provides the inside relation among them and in conclusion it informs the reader to be attractive. In this small passage some important (relevant) signs take part in organizing the text. First of all, we should like to state the role of anaphora. The rhetoric role of the pronoun serves to draw the facts what happened in this microtext. It doesn't serve to express that who performed the happened things (Veyselli, 2010).

As we stated above, using rhetoric means a writer performs pragmatic and cognitive functions in the text. Using these means in a artistic discourse the writer tries to send his pragmatic purpose to the reader. At the same time, these rhetoric means have very cognitive purpose for the receiver as well (Mammadov \& Mammadov, 2007). The main purpose of the writer is to introduce the inside text of the artistic discourse using the most effective way and attract the reader's attention at the beginning. The artistic discourse that has been riched and persuadedin various interesting metopforical stylies creates active verbal communication between the sender and the receiver basing on attraction-persuation- cognition. The created image is considered to be the result of intellectual activity of the writer. It is necessary to state that the fact that the receiver gets from the sender depends on his (the receiver's) inside logical thinking. During this accepting process the choice between rhetoric and polemic argumentation appears. D. Schiffrin writes: "The rhetoric argumentation is realized in the monologue text, and it doesn't face the obstacles of the other opponent's demonstrating his position". We should like to state that both of these factors are realized in the artistic discourse depending on the semantic meanings. This case demonstrates the pragmatic purposes of the sender of the text. The writer introduces the purpose of the text in the explicit way and tries to make his reader think. The writer is also able to make his reader think about the hidden idea in the text in the implicit way. It depends on the writer's ability.

The realization of the rhethoric and polemic factors in fiction are formed the cognitive structure of the artistic discourse. For instance, though the metophoric expressions like grammatical and lexical elements serve the argumentation, the differences they make prefer the cognitive opperations in the receiver of the text. 
The predictable unitsare not expressed with their literary meanings, but they are expressed with the figurative meaningsin the artistic discourse. This is known as an analogical means. Look at such an example:

\section{Life's but a walking shadow; a poor player,}

\section{That struts and frets his hour upon the stage.}

If we break down a metaphorical statement into its component parts, the real-world subject (first item) in a metaphoric statement is known as the tenor. The second item (often an imaginary one or at least not present in a literal sense) to which the tenor refers is called the vehicle. For example, consider the metaphorical statement, "Susan is a viper in her cruel treacheries." Here, Susan is the tenor in the metaphor, and viper is the vehicle in the same metaphor. The tenor, Susan, is literally present or literally exists. The vehicle, the hypothetical or imagined viper, is not necessarily physically present.

One of the ways or technics to send the artistic discourse to the auditorium is epiphora. Epiphora (also called epistrophe) is a greek word meaning "to bring" is a rhetorical device that creates emphatic repetition of a word or phrase placed at the end of several sentences. The rhetorical pattern creates rhythm, and it creates flow within the text.

... this nation, under God, shall have a new birth of freedom — and that government of the people, by the people, for the people, shall not perish from the earth.

(Abraham Lincoln in the Gettysburg Address)

As we see, the word "the people" is used in the repeating form in a sequence of words for emphasizing the speaker's idea. Abraham Lincoln used the word "the people" in his speech and emphasized that the government is not abstract, distant notion; the government has a strict, close relation with the people. The repetition of the word creates a strong rhetoric style in the discourse. Other example:

The United States, as the world knows,

will never start a war.

We do not want a war.

We do not now expect a war. (John F. Kennedy, "The Strategy for Peace”, June 10, 1963)

Again the same rhetoric device is used. Using the epiphorain the artistic discourse attracts the reader's or listener's attention. We should like to draw your attention to the fact as epiphora is used at the end of the words, sentences, phrases, and it is one of the best rhetoric means for to attract the auditorium. We can say the same words about the diaphora too. Diaphora is a repetition of a common name so as to perform two logical functions. It designates an individual and signifies the qualities connoted by that individual's name or title. The writer uses this rhetorical means to bring emotion, rhythm, pace and atmosphere to the discourse. For instance:

The book is not the book that you take to read it, but because of its exaggeration cannot read it till the end.

\section{Conclusion}

The rhetoric means have a great role in the effectiveness in the artistic discourse. Using the rhetoric means such as anaphora, epiphora, diaphora, methaphor etc. the mind of the receiver evokes, the explicit and the implicit meaning of the text becomes clear and the attraction of the listener's attracted by. The attraction is the main point in the artistic discourse. By this the writer can attract any auditorium. The roles of rhetoric means in the artistic discourse make the discourse be comprehensive, complete, and meaningful. These facts provide speech intension in artistic discourse. Therefore using rhetoric means in the artistic discourse is the writer's main goal from the beginning of his work. The rhetoric figures decorate the artistic discourse and it causes the discourse to be more effective. Rhetoric means cover lexical and syntactic constructions, as well as various figurative expressions. The limit of the rhetoric figures is boundless: rhetoric questions, syntactic repetitions, inversion, synonyms, homonyms, antonyms, hints, anaphora, epiphora, alliteration, diaphora, taboos, appositions, literary particles etc. Each of these has a great influence for to increase the effectiveness of the artistic discourse.

The representatives of the ancient Greek Schools, Aristotle, Lessing, Didro, comprehensive linguistics and literary critics state the importance of using rhetoric means, poetic figures, various metaphors etc. in the artistic discourse.

\section{References}

Abdullayev, S. (2013). Experience of fuzzy linguistics. Bakı. 
Enkvist, N. E. (1989). From Text to Interpretability: A Contribution to the Discussion of Basic Terms in Text linguistics. In W. Heydrich (Ed.), Connexity and Coherence: Analysis of Text and Discourse. Berlin, New York: Mouton de Gruyter. http://dx.doi.org/10.1515/9783110854831.369

Halperin, I. R. (1981). Text as an object of linguistic research. Moscow: Nauka.

Mammadov, A., \& Mammadov, M. (2007). Cognitive structure of the text. Vestnik MGLUV Moscow: Rema.

Mammadov, A., \& Mammadov, M. (2010). Cognitive pospects of discourse analysis. Baku.

Schiffrin, D. (n.d.). Everyday Argument: Organization of Diversity in Talk. In T. A. van Dijk (Ed.), Handbook of Discourse Analysis (Vol. 3). London: Academic Press.

van Dijk, T. A. (1998). Ideology: A Interdisiplinary approach. London: Saga Publications.

Veyselli, F. Y. (2010). Introduction of discourse analysis. "Tehsil” NPM, Bak1.

Wittgenstein, L. (1953). Philosophical Investigations. New York: Oxford University Press.

Wodak, R. (1992). Vocabularies of public life: Empirical essays in symbolic structure. London: Longman.

Zaychikova, N. (2003). Political text-political discourse-political novel. In Polyphony education and English studies in a multicultural world. Proceedings of the first international conference of the Association of English teachers. November 25-26, Moscow State Linguistic University, Moscow

\section{Copyrights}

Copyright for this article is retained by the author(s), with first publication rights granted to the journal.

This is an open-access article distributed under the terms and conditions of the Creative Commons Attribution license (http://creativecommons.org/licenses/by/3.0/). 